\title{
¿Es válido atribuir la polarización política a la comunicación digital? Sobre burbujas, plataformas y polarización afectiva*
}

Is it Valid to Attribute Political Polarization to Digital Communication? On Bubbles, Platforms and Affective Polarization

\section{SILVIO WAISBORD**}

George Washington University, Estados Unidos.

waisbord@gwu.edu

https://doi.org/10.46468/rsaap.14.2.A1

El propósito de este trabajo es desentrañar la relación entre la comunicación pública y la polarización política contemporánea. A partir de una revisión de la literatura global reciente, se plantea que la polarización es el producto de la combinación de fenómenos políticos y comunicacionales. Es equivocado entender la polarización como un producto únicamente asociado con tendencias de la comunicación digital. Es necesario reconocer la corrida hacia posiciones más extremas de los populismos y la pérdida y fragmentación de posiciones moderadas (a izquierda o derecha) como así también el papel de los medios "tradicionales" en fomentar la polarización afectiva. La sobrerrepresentación de fuertes sentimientos políticos sumado al poder de movilización de clivajes sociales y culturales que apelan a identidades colectivas en medios tradicionales y sociales profundiza oposiciones binarias. La polarización como estrategia política y mediática rinde frutos. En la comunicación mediatizada actual, apelar a discursos polarizantes tiene rédito, ya sea en términos de audiencia y publicidad como asi también de compensaciones simbólicas en plataformas digitales — seguidores, popularidad, relevancia. Asimismo, la desigualdad en la participación politica, inclinada a favor de personas con fuertes sentimientos partidarios e ideológicos, y la popularidad de medios de información que apuntan a alimentar y azuzar tales sentimientos también apuntala la polarización.

\section{La polarización como problema}

La discusión global sobre comunicación, medios y polarización política continúa atrayendo atención de varias disciplinas a la luz de fenómenos

* Artículo recibido el 10 de marzo de 2020 y aceptado para su publicación el 14 de julio de 2020

** El autor agradece el aporte de dos evaluaciones anónimas a una versión previa de este artículo. 
políticos de las últimas dos décadas, específicamente los populismos y la afirmación de la extrema derecha y el discurso del odio. Si el espíritu de época en las postrimerías de la Guerra Fría fue un enorme optimismo sobre la democracia liberal, hoy en día la sensación dominante es diferente. Se expresa en la preocupación por el futuro de la democracia, en parte debido a la creciente polarización política.

La polarización es generalmente vista como un desafío para la democracia, en tanto que ésta demanda formas de negociación y compromiso entre diferentes fuerzas políticas. La polarización lleva al extremismo actitudinal y político como así también al rechazo y la expulsión de intereses y actores. La polarización azuza movimientos extremistas y socava las bases necesarias para un régimen político que demanda aceptación de la diversidad de opiniones, mínima estabilidad, transición pacífica de poder, moderación, constante negociación y reconocimiento de adversarios.

El escepticismo sobre las condiciones actuales de la democracia y los temores sobre la polarización adquirieron enorme visibilidad después de 2016. El triunfo del Brexit y el ascenso de Donald Trump a la presidencia de los Estados Unidos fueron interpretados como señales inequívocas de la agudización de la polarización. El triunfo de posiciones de derecha, ancladas en identidades racistas y xenofóbicas en ambas márgenes del Atlántico Norte sumados a casos en el Sur Global como Brasil, India y Filipinas, son comúnmente citados como ejemplos de sociedades polarizadas. En América Latina, la tendencia en alza del populismo de "izquierda" en la primera década del siglo veintiuno reanimó debates sobre la polarización y sus consecuencias (de la Torre y Peruzzotti, 2008). Por un lado, una posición, asentada en la teoría democrática liberal, vio con preocupación al populismo representado más cabalmente por el chavismo venezolano como esencialmente predispuesto a acelerar la polarización y, por ende, como amenaza a la democracia. Por otro lado, la posición a favor del populismo entendió que sus tendencias polarizantes son profundamente democráticas, en tanto apuntaban a un reequilibrio político y a la constitución de un frente contrahegemónico.

En su clásica definición, Giovanni Sartori (1976) entiende la polarización como la distancia ideológica entre candidatos, partidos y/o votantes. Esta definición centrada en la política formal precisa ser contextualizada como un proceso más amplio, en tanto la polarización política solamente se puede entender como epifenómeno de tendencias sociales. El grado de polarización política se puede medir de varias formas: las políticas y las plataformas de partidos y gobiernos; las actitudes, discursos y votos de parlamentarios; y las dimensiones afectivas de la ciudadanía tanto sobre otros miembros de sus partidos como también sus sentimientos, aprecios y odios sobre personas de diferente afiliación política. 


\section{Silvio Waisbord}

Aquí entiendo a la polarización como el proceso por el cual las multiplicidades de diferencias políticas crecientemente se alinean en una sola dimensión, y la política es percibida y definida como un eterno conflicto "entre nosotros contra ellos" (McCoy et al, 2018). La polarización simplifica la complejidad de las relaciones políticas y sociales en tanto cualquier diferencia se licúa en una sola dimensión. La polarización aglutina divisiones que no están necesariamente vinculadas con preferencias políticas e identidades sociales, debilita otros clivajes divisorios y genera/refuerza dos bloques diferentes que se entienden como mutuamente excluyentes. La polarización política implica el dominio de la identidad partidaria/ideológica sobre otras formas de identificación y acción política (Iyengar et al,2012)

La teoría democrática fundamentalmente entiende a la polarización como una tendencia negativa. Si bien las divisiones son esenciales e inevitables en la política, la polarización exacerba conflictos que pueden desembocar en opciones políticas contrarias a valores democráticos. La polarización socava las posibilidades del reconocimiento y aceptación de opiniones diversas y conlleva al simple mayoritarismo que desconoce o impone su voluntad sobre los intereses minoritarios. De ahí que la democracia funcional y la polarización están inversamente relacionadas (Sani y Sartori, 1980).

Entendiendo a la democracia como un sistema para expresar o resolver diferentes intereses sociales de manera pacífica sobre la base de reglas con consenso (Przeworski y Sprague, 1986), la polarización dificulta o directamente se opone al consenso. La democracia puede existir a pesar de la polarización política, pero esta permanece como amenaza constante en tanto dificulta la negociación y la concesión, refuerza prejuicios contra otros, y debilita el prestigio y la confianza en las instituciones democráticas (en tanto son vistas como partidarias de uno u otro bando). La polarización abona el terreno para fenómenos y movimientos antidemocráticos interesados en ignorar y excluir por recursos legales o por la fuerza a otras fuerzas políticas. Las consecuencias a largo plazo son instituciones públicas débiles, proclives a ser controladas y operadas según criterios estrictamente partidarios, sin preocupación por el "bien común". En estas circunstancias, no sorprende el (re)surgimiento de fenómenos autoritarios que alimentan la polarización, en tanto conciben que tensar las tensiones existentes es necesario para conseguir el poder y permanecer en él.

Por el contrario, los críticos de la democracia postulan que la polarización es inevitable, saludable y necesaria. Como critica filosófica al liberalismo político y visión que alienta la superación de las "trampas" de la democracia, el populismo contemporáneo es quizás el representante más notable de esta tradición que endorsa la polarización (Laclau, 2005). Desde su concepción de la política como finamente dividida entre amigo/enemigo, entiende que la 
polarización es un proceso necesario e inevitable de agudización de diferencias. La política es concebida como naturalmente dividida en campos irreconciliables, y como estrategia para marcar y profundizar las divisiones. No da cabida a la política como espacio de encuentro de la multiplicidad de intereses y la resolución de conflictos de forma que se diriman posiciones heterogéneas. Las divisiones son permanentes y deseables en tanto la política es entendida como juego de suma cero. La disputa por el poder desemboca en ganancias y pérdidas a un lado u otro. Entiende que la política dividida en dos campos finamente definidos y acérrimamente opuestos es inevitable —el "pueblo" contra las "elites". Cualquier otra división es superficial y eventualmente se diluye en la separación fundamental y fundacional de la política. La sentencia de Steve Bannon, ideólogo original del trumpismo y factor fundamental del fenómeno Breitbart en el espacio mediático norteamericano, es ilustrativa de esta mentalidad: "Si quieres hacer cambios profundos en la sociedad, primero hay que dividirla". Mientras que la democracia entiende que el agonismo es central y el consenso necesario y difícil, el populismo entiende la política como puro antagonismo y desecha la posibilidad de consenso.

\section{Las causas de la polarización}

Sin duda, la polarización no es nueva. Cada momento de colapso democrático y ascenso autoritario está anclado en momentos de aumento de la polarización. A lo largo del siglo veinte, tanto las revoluciones de izquierda como las restauraciones y reacciones conservadoras culminaron en periodos de agudización de la diferencia y auge de concepciones sobre el otro como enemigo acérrimo, que debe ser expulsado de la comunidad política. La exacerbación de la polarización lleva a posiciones que excluyen al adversario en tanto no se le reconocen igualdad de derechos. Estas condiciones hicieron imposible cualquier intento de consenso y negociación. La experiencia histórica muestra que la estabilidad democrática demanda cierto grado de acuerdo sobre reglas fundamentales tanto entre elites políticas como en la ciudadanía. Sin consensos mínimos, el peligro de la polarización es constante.

Por cierto, la historia política de América Latina se caracteriza por olas de polarización que desembocaron en periodos autoritarios (Bornschier, 2019). Los golpes de estado fueron expresiones de sectores políticos, económicos y sociales empeñados en polarizar sociedades para lograr y mantener el poder.

Por lo tanto, si la polarización no es un fenómeno nuevo, ¿cómo explicar su efervescencia en la escena política contemporánea? ¿Por qué aparece como fenómeno común el hecho de que sea un atributo en sociedades políticas con marcadas diferencias históricas? 
Frente a estas preguntas, los estudios de comunicación pública, medios y periodismo se han focalizado en una serie de preguntas. ¿Es coincidencia la simultaneidad de la polarización política con el ascenso de la política digital, especialmente el rol preponderante de los "medios sociales"? ¿Se puede establecer una clara e inequívoca relación causal entre factores comunicacionales y políticos? ¿Qué explica que en países con históricas diferencias en sistemas de medios y sistemas políticos hayan surgido tendencias similares de fortalecimiento de identidades partidarias, el debilitamiento de posiciones y de fuerza del centro, el triunfo de movimientos políticos como el populismo que agudizan procesos de polarización? ¿Hay tendencias intrínsecas/estructurales del sistema político-mediático contemporáneo que promueven la polarización en diferentes contextos? ¿Cuál es la articulación de la dinámica de polarización de elites y polarización de ciudadanos con la comunicación pública?

Puesto que es un tema situado en el cruce de procesos comunicacionales y políticos, las respuestas se focalizan en ambos procesos. Las relaciones causales no están claras puesto que hay múltiples fenómenos concurrentes que parecieran contribuir a la polarización. Aquí es necesario desbrozar la nutrida literatura que considera variables comunicacionales y políticas. No hay explicaciones fáciles ni argumentos simples para comprender un fenómeno multifacético que, aun cuando ofrezca aspectos similares a nivel global, tiene sus particularidades ancladas en características nacionales.

Las explicaciones sobre la polarización como fenómeno comunicativopolítico se pueden agrupar en dos líneas argumentales.

Una línea enfatiza la importancia de fenómenos comunicacionales. La fragmentación de los sistemas de medios hace posible el consumo de contenidos ajustados estrictamente a intereses e identidades particulares (Prior, 2007). La fragmentación posibilita y refuerza fuertes identidades políticas que, supuestamente, fortalecen actitudes contrarias a la democracia en tanto que no son conducentes a la exposición y el diálogo en la diferencia o la búsqueda de puntos comunes con adversarios.

Asimismo, la globalización de la comunicación acelera similitudes en sistemas nacionales de medios con notables diferencias históricas (Birkinbine et al, 2016). La mediación digital de la política genera procesos similares, en tanto las compañías y las plataformas tecnológicas operan de forma similar y según los mismos criterios empresariales. El ascenso fulminante de los medios sociales como plataformas dominantes desde fines de la década pasada son cruciales, puesto que han fagocitado el tráfico (y la publicidad) en Internet. Los algoritmos de los medios sociales tienden al reforzamiento de actitudes; la expansión y la sofisticación de la desinformación son tendencias globales. 
Esta posición mezcla diferentes procesos y causas que atribuyen la polarización a diferentes actores y procesos — desde el surgimiento de los noticieros de cable hasta el formato particular de breves intervenciones en Twitter, desde los patrones de búsqueda en Google hasta los grupos cerrados de Facebook y de Whatsapp.

Otra línea argumental atribuye la polarización a procesos esencialmente políticos. La arquitectura institucional inclina a determinados sistemas políticos a ser proclives a la polarización. Sistemas de gobierno, sistemas electorales, sistema de partidos, tipo representación partidaria en el Congreso, y otros factores promueven la polarización o la moderación. Obviamente, el caso de Estados Unidos sobresale debido a su estructura presidencialista, bipartidismo y sistema de elecciones, factores que colocan en potencia la posibilidad constante de polarización a diferencia de los sistemas parlamentarios y multipartidistas. Sin embargo, la polarización no fue rasgo distintivo y dominante a lo largo de la historia norteamericana. La polarización actual es particularmente notable en comparación al relativo consenso de elites y públicos durante el periodo de la posguerra.

Además de cuestiones de diseño institucional, esta línea explicativa enfatiza el papel de las elites en la polarización y las actitudes ciudadanas. Cuando las elites toman decisiones de confrontación constante y excluyen la cooperación como opción, fomentan la polarización (Bermeo, 2003). La polarización no está determinada o ligada necesariamente a cuestiones institucionales. De hecho, es posible pensar que aun cuando un sistema político tenga desvíos estructurales que graviten hacia posibles extremismos, la opinión pública opera como contrapeso en tanto está relativamente satisfecha con el orden político, la situación económica, y otras cuestiones. Por eso, las decisiones que toman las elites políticas son importantes. Cuando las elites optan por intensificar la polarización, apelando a discursos que ahondan diferencias y cuestionan la legitimidad de las instituciones públicas, aceleran la polarización.

Al mismo tiempo, las señales que las elites envían a sus partidarios son importantes. Esta es una vieja discusión sobre si las elites o la ciudadanía cargan con mayor responsabilidad en dinamizar y exacerbar la polarización. Cuando las elites se polarizan y tienen menos incentivos para la negociación y el consenso fomentan divisiones en la ciudadanía a través de la apelación a temas que dividen y movilizan. Su posición "polarizante" no es producto de la creciente extremización popular, sino que es el resultado de dinámicas localizadas en las elites y diseños institucionales particulares que favorecen dividir más que buscar consensos. Este proceso de polarización "desde arriba" lleva a mayor polarización actitudinal en la ciudadanía que, a su vez, retroalimenta las decisiones de las elites. 


\section{Silvio Waisbord}

\section{La importancia del contexto mediático y político}

Aquí presento el siguiente argumento: La polarización es el resultado de la agregación de procesos comunicativos-políticos que obedecen principalmente a decisiones de elites políticas y mediáticas más que a procesos predeterminados por la política digital o especialmente las "plataformas sociales". Tanto cuestiones políticas como aspectos de los sistemas nacionales de medios permiten explicar la intensidad de la polarización. Que la polarización no sea una tendencia idéntica o con la misma intensidad en diferentes países y diferentes periodos nos hace preguntar sobre los factores que explican la diferencia. No pareciera que haya evidencia contundente para argumentar que la polarización es inevitable y que está asociada con supuestos efectos homogéneos de las plataformas digitales, especialmente los "medios sociales" (Settle, 2018).

Mi posición difiere de explicaciones según las cuales la polarización es resultado únicamente de dinámicas comunicacionales/mediáticas o políticas. La evidencia es compleja e insuficiente para sugerir que haya procesos unidireccionales y causales relativamente simples. La polarización no está ligada inevitablemente al impacto o tendencias de una plataforma o a la fragmentación de la comunicación pública. No hay un solo tipo de medio/ plataforma que unilateralmente "polariza". En cambio, hay procesos mixtos en la comunicación política que permiten explicar más convincentemente los flujos de des/polarización.

Estudios recientes (Fletcher et al,2020) llaman la atención sobre aspectos fundamentales y relativamente obvios que, sin embargo, suelen ser ignorados en la discusión desprolija sobre la polarización contemporánea: los niveles de polarización varían en países democráticos, son más altos en sistemas presidenciales y procesos electorales que tienden al bipartidismo, y son intensificados tanto por medios tradicionales (prensa y radiodifusión) y digitales, especialmente en países con una fuerte tradición de medios "partidarios", cercanos a fuerzas políticas e ideológicas, y de medios públicos débiles o sujetos estrechamente al poder político.

Dadas estas condiciones, hay que afinar el análisis para entender por qué la polarización no tiene la misma intensidad en diferentes países y regiones. No hay que asumir que inevitablemente tendencias estructurales de la comunicación digital conducen a la exacerbación de conflictos y al reforzamiento de los extremos.

No hay duda de que la fragmentación mediática refuerza la política de identidades dentro de un arco de izquierda a derecha, en tanto facilita la producción de contenidos que se ajustan perfectamente a simpatías políticas determinadas. Sin embargo, tales dinámicas no son absolutamente nuevas, 
puesto que la existencia histórica de sistemas de medios con fuerte extracción y anclaje identitario (partidario, religioso, ideológico, étnico, racial) no necesariamente desembocó en altos niveles de polarización. De hecho, el estrecho "paralelismo" entre medios y política durante el siglo pasado en Europa Occidental no se materializó en niveles similares de polarización. Tampoco hay niveles similares de polaridad afectiva en la actualidad aun cuando la política digital haya adquirido centralidad. Que haya medios fuertemente partidarios o ideológicos, alineados con fuerzas políticas, no determina la polarización.

Ciertas condiciones políticas son responsables por activar ecologías informativas con tendencias latentes a fomentar identidades polarizadas. Por lo tanto, es necesario analizar procesos políticos, el rol de las elites y el tenor de las ideologías de las fuerzas mayoritarias para entender si tendencias estructurales de la comunicación masiva efectivamente polarizan. Sugiero que el ascenso reciente del populismo, con su visión de la política como la constante profundización de divisiones y la imposibilidad de consensos, explica la dinamización de la comunicación polarizante. Consecuente con esta visión, el populismo entiende a los medios y la comunicación pública desde una concepción binaria y extrema, interesada en cultivar sentimientos hostiles contra medios críticos y sus audiencias. La combinación de liderazgos populistas con ecologías informativas, que incluyen medios tradicionales y digitales, factibles de ser utilizadas para explotar divisiones y resentimientos ayuda a entender la polarización.

\section{Polarización y arquitectura de la comunicación pública}

No es sencillo desentrañar la relación entre la polarización y la contemporánea arquitectura de la comunicación pública. Hay una nutrida literatura norteamericana y europea sobre diversos aspectos de este tema, que identifica diferentes procesos y posibles relaciones causales. Veamos sus líneas principales para después analizar si son aplicables al caso latinoamericano.

Un argumento común en el sistema contemporáneo de medios es más proclive a la polarización a diferencia de los sistemas de comunicación masiva durante el siglo veinte (Tucker et al, 2018). La consolidación de una comunicación pública más mediatizada, fragmentada y de opciones múltiples es diferente respecto de la era moderna de los medios masivos cuando las opciones eran sensiblemente más limitadas. Con sus múltiples puntos de entrada y ofertas incalculables en internet, el sistema actual ofrece contenidos que pueden ajustarse a intereses e identidades políticas particulares.

Cuando las empresas de medios, especialmente en televisión, apostaban a congregar a públicos masivos, el contenido tendía a ser menos partidario o 


\section{Silvio Waisbord}

ideológico puesto que el propósito central era evitar ofender a audiencias o anunciantes. Los incentivos del mercado mediático eran producir contenidos masivos para atraer enormes audiencias que, a su vez, eran vendidas a la publicidad. Con el propósito de sumar públicos se preferían contenidos que no ofendieran sensibilidades que pudieran ahuyentar potenciales consumidores, ya fueran partidarias o de otro tipo. Los contenidos periodísticos, como ilustra el caso de la televisión comercial y la prensa escrita en Estados Unidos, intentaban estar colocados en un mítica línea central y moderada que fuera de similar interés para públicos diferentes. La virtual condición de monopolios y oligopolios favorecía el contenido que no fuera abiertamente partidario o tratara de ser imaginariamente imparcial. Los sistemas de radiodifusión pública operaban en línea parecida debido a la legislación existente, expectativas públicas y cálculos políticos: congregar públicos masivos con contenidos de interés "común” y servir a la ciudadanía en general.

Esta situación sufrió importantes alteraciones en las últimas décadas. Sucesivas innovaciones tecnológicas y comerciales erosionaron el modelo pasado, con la llegada de la televisión por cable y satélite y la fragmentación del mercado radial debido a una mayor capacidad y calidad del sonido. En los sistemas comerciales, la creciente "nichificación" de las audiencias de medios fue apoyada y alentada por el mercado publicitario interesado en apuntar a cortes de consumidores cada vez más especializados y diferenciados según variables sociales y parámetros de consumo (Turow, 1997). Internet fue la culminación de este proceso de fragmentación de públicos al facilitar la proliferación de contenidos y el relativamente fácil acceso a la producción y distribución de contenidos. Este modelo fue exitoso en términos comerciales en tanto concentró consumidores y anunciantes.

Así como este proceso de segmentación llevó a la construcción de grupos definidos de consumidores (especialmente de mediano y alto poder de consumo), también alimentó la producción de contenidos ajustados a identidades políticas. La mayor diversidad abre la posibilidad de medios orientados a segmentos particulares de afiliación y simpatía política, ya sean noticieros por cable, estaciones de radio o sitios digitales.

La fragmentación mediática no solamente refuerza la fragmentación política y social y genera condiciones para reforzar simpatías, diferencias y odios. También disminuye la capacidad y la presencia de sistemas públicos o privados que graviten hacía la imparcialidad o contemplen y den espacio a diferentes posiciones.

Por lo tanto, la polarización como producto de tendencias mediáticas no es atribuible a una sola plataforma, canal o compañía/medio, sino que está vinculada a la tendencia general de fragmentación y proliferación de contenidos segmentados según simpatías partidarias e ideológicas. La suma 
de tendencias tecnológicas, la desregulación de mercados de medios, y la puja de intereses comerciales y publicitarios terminó produciendo un escenario mediático de segmentación política-comunicacional.

En esta línea argumental subyace la conclusión de que los sistemas contemporáneos de medios favorecen la polarización puesto que los medios que cultivaron un periodismo "moderado" en Estados Unidos atraviesan una grave situación. La crisis sin precedentes de la industria de diarios fue responsable del cierre y del achicamiento de cientos de medios que practicaron un periodismo desinteresado en acentuar identidades partidarias o ideológicas. La pérdida de estos medios está correlacionada con el aumento de la polarización; en distritos donde se registraron pérdida de medios "moderados" se encuentraa un mayor nivel de polarización en años recientes. El presunto impacto no es que es deliberadamente "moderan" las actitudes políticas, sino que no agitan activamente identidades políticas extremas (Darr et al, 2018).

Obviamente, estos argumentos no se aplican perfectamente en América Latina. Los medios tradicionales, aun durante la época de auge de los medios "masivos", no apelaron necesariamente a contenidos periodísticos presuntamente neutrales o imparciales para captar grandes audiencias. El modelo empresarial fue diferente. No estuvo solamente anclado en la búsqueda de anunciantes privados, sino que tuvo (y continúa manteniendo) un significativo apoyo económico de parte del Estado a través de publicidad, subsidios, quitas impositivas, y otras tácticas. Por lo tanto, la neutralidad periodística como estrategia mercantil nunca tuvo el mismo impulso ni tampoco la fortaleza misma del periodismo como profesión. Esto explica por qué las preferencias ideológicas de los medios periodísticos fueron claras según intereses políticos, económicos, y personales entrelazadas con el poder político y económico. Fueron directamente responsables por agitar sentimientos partidarios e ideológicos justamente en la dirección de la polarización según agendas editoriales. La imparcialidad no fue un "negocio" viable o necesario. Los medios fueron híbridos privados con generosa financiación estatal (Waisbord, 2000a).

Asimismo, la debilidad histórica de los sistemas públicos de medios como entes "públicos" sujetos a la voluntad del Poder Ejecutivo y a las vicisitudes políticas-partidarias no sentó las bases para un periodismo que intentara ser equidistante de las fuerzas políticas en pugna. Cuando los medios públicos tenían (y continúan en gran medida) línea directa con el ejecutivo y actuaban con limitada autonomía de la política (en el mejor de los casos), no existieron posibilidades para un periodismo neutral, imparcial o equilibrado - es decir, un periodismo que no estuviera sujeto a la potenciación de intereses puramente partidarios (Waisbord, 2000b). 


\section{Silvio Waisbord}

Esta ausencia es importante por varias razones que van más allá de la polarización, como la importancia de sistemas públicos que reflejen el pluralismo de voces y la diversidad de temas propias de cualquier sociedad. En términos de la polarización, la carencia de medios públicos con agendas periodísticas públicas (es decir, no estrictamente partidarias u oficialistas) es fundamental, en tanto contribuyen a la producción de información de interés "general" que no está atada a la lógica de ahondar diferencias. Esta conclusión sobresale en trabajos sobre la importancia de los medios públicos europeos como amortiguadores de la posible polarización afectiva y cognitiva (Dahlgren, 2019).

Por lo tanto, la arquitectura mediática en América Latina careció de estructuras e incentivos que impulsaran un periodismo moderado en términos de identidades partidarias o ideológicas. No tuvo resguardos potenciales frente a la polarización en tanto las alianzas políticas y el paralelismo político-mediático fueron características esenciales de los sistemas nacionales de medios (Guerrero y Marquez, 2014). No hubo una presunta división férrea entre intereses editoriales, comerciales y periodísticos que apuntalaran un periodismo que intentara o pretendiera ser equilibrado.

La debilidad histórica de empresas periodísticas comprometidas con la producción de información balanceada ayuda a explicar tendencias polarizantes en las democracias latinoamericanas del último siglo. Ni el periodismo en medios comerciales consensuó o mantuvo estándares de relativa imparcialidad o neutralidad, ni los medios públicos efectivamente funcionaron como plazas amplias e inclusivas de información equilibrada y renuente a tomar posiciones partidarias claras. Esta característica es importante para entender la polarización, en tanto la evidencia sugiere que el consumo de información producida por medios públicos, que pugna por mantener estándares de neutralidad y dar lugar a diferentes perspectivas, está negativamente relacionado con la polarización.

En este contexto, ¿qué hay de nuevo con las enormes transformaciones de las últimas décadas hacia mercados de medios segmentados? Si hoy existen fuertes incentivos para periodismos abiertamente partidarios e ideológicos, ¿qué innovaciones trajeron las sucesivas oleadas de innovaciones tecnológicas y corporativas que desembocaron en los actuales mercados de nichos "políticos"? ¿Son estos nichos más polarizantes que la prensa del pasado que abiertamente defendía causas partidarias e ideológicas?

Tanto en el pasado como en la actualidad hay tendencias que favorecen la producción de contenidos periodísticos ajustados según simpatías políticas e ideológicas. Es decir, no pareciera que la transición hacia sistemas de medios de nichos políticos sea un rasgo absolutamente novedoso. Sigue siendo redituable producir contenidos para segmentos de fuerte identidad 
partidaria, ideológica o aliados con determinadas fuerzas políticas y personalidades en coyunturas específicas. Hay audiencias politizadas y/o que siguen la política de cerca que son ávidas de opciones periodísticas parcializadas. Asimismo, esta opción como estrategia de mercado genera rédito económico, especialmente cuando las empresas son cercanas a los gobiernos que premian su lealtad con apoyos diversos.

Considerando la trayectoria de los medios latinoamericanos, es válido preguntarse si la existencia del paralelismo mediático entre política y sistema de medios necesariamente conduce a la polarización. ¿̇es la polarización la consecuencia necesaria e inevitable de la proximidad entre medios y fuerzas políticas/ideológicas?

Tengamos en cuenta que las democracias europeas, sin excepción, mostraron un alto grado de paralelismo durante gran parte del periodo de posguerra. Sólidos y distintivos bloques ideológicos -la democracia cristiana, el socialismo, el liberalismo y otras fuerzas - tuvieron expresión en la prensa. Los medios privados tuvieron cercanía e identificación con causas ideológicas y políticas, como los tabloides populares o la prensa "de calidad". Sin embargo, esta situación no llevó a la agudización de las simpatías afectivas que contribuyera a la polarización. No pareciera que la presencia de medios "partidarios" sea condición suficiente para la polarización. Su importancia, sin embargo, no puede ser descartada. No es una cuestión principalmente de existencia de medios "ideológicos" que ofrezcan visiones unilaterales y sesgadas que endiosen a los propios y demonicen a los contrarios.

Una cuestión clave es el tenor de las ideologías propagadas por medios con abiertas simpatías políticas. No es un problema puramente de línea editorial y financiamiento, sino de tipo de contenido. Este tema se vincula con la responsabilidad particular de ciertos medios, plataformas y empresas en alentar la polarización. Es decir, la sola presencia de medios "partidizados" no lleva a la polarización, sino que depende del tipo de creencias y actitudes que estimulen. Los medios pueden ser catalizadores de sentimientos que refuercen determinadas ideologías y simpatías por políticos y funcionarios, pero por sí solos no alimentan actitudes polarizantes a ambas bandas del escenario político. El tenor de la identidad partidaria - propuestas políticas, visión de la democracia, creencias sobre adversarios- es importante para descifrar la vinculación entre medios cercanos o abiertamente identificados con partidos y causas y la agudización de la polarización.

Es necesario enfatizar el protagonismo de ciertos medios en cultivar y agitar la polarización afectiva — es decir, la intensificación de sentimientos políticos que valoran ciegamente a los propios sin consideraciones ulteriores, y expresan profundo desprecio hacia los otros. La polarización no es simplemente o principalmente el resultado de la presencia de un arco de 
medios partidarios o ideológicos en sistemas con limitado pluralismo. Se relaciona con las características particulares de determinadas empresas de medios y del periodismo que practican - la cobertura de la política, la visión de adversarios, la definición de las causas e ideologías, la aproximación a temas que son eje de identidades políticas.

Desde esta perspectiva, estudios recientes responsabilizan a medios (ultra)conservadores como responsables de la polarización de la derecha en varios países. La cadena de noticias de cable Fox en Estados Unidos (Peck, 2019), los comentaristas radiales que comandan enormes audiencias como Rush Limbaugh, los tabloides racistas y xenófobos de la cadena Murdoch y medios similares en Europa, y los medios de propiedad estatal y controlados por líderes populistas en Europa del Este (Szabo et al,2019) han contribuido a la polarización mucho antes que sitios similares digitales actuaran azuzando sentimientos extremistas.

Estos medios deliberadamente optan por agitar sentimientos polarizantes cuando habitualmente hablan en tono despectivo y agresivo sobre "otros" que son vistos como el enemigo de sus audiencias. Es decir, no son simplemente una manifestación del paralelismo partidario o ideológico de antaño, sino que construyen contenidos noticiosos deliberadamente diseñados para intensificar miedos hacia otros y ahondar sentimientos de víctimas en sus audiencias. Sus agendas editoriales están claramente destinadas a alimentar y provocar prejuicios. Son medios puramente "identitarios", polarizantes en el sentido de que incasablemente cultivan y mantienen identidades políticas que operan en una doble sintonía polarizante: reforzar sentimientos de pérdida de estatus económico, social y cultural en un grupo definido por raza, ciudadanía, religión, género, sexualidad y otras variables, y satanizar al resto.

Aquí la evidencia sobre el impacto de medios "partidarios/ideológicos" sobre la polarización es sólida, especialmente en el caso del electorado de derecha en Estados Unidos (Garrett et al,2019). Existen efectos tangibles de reforzamiento mutuo entre medios y audiencias en múltiples planos. Quienes más consumen tales medios son más proclives a expresar actitudes hostiles frente a quienes piensan distinto — poblaciones usualmente estigmatizadas y criticadas por el periodismo. Sus contenidos, plenos de virulencia hacia los adversarios, se filtran en el amplio espacio comunicacional- la cobertura de otros medios, los posteos y las discusiones en plataformas digitales, y discursos públicos. Además, el periodismo empeñado en azuzar diferencias tiene amplia llegada e influencia en elites políticas conservadoras que se hacen eco de la cobertura periodística y de columnas de opinión, y que aparecen con frecuencia en los mismos medios.

Así se consolida un círculo vicioso de medios-elites-ciudadanos que trafican información con objetivos claros: reforzar identidades reaccionarias y 
denostar al adversario como enemigo (Levendusky, 2019). Quienes polarizan al electorado no son "los medios" en términos generales, ni siquiera los medios abiertamente ideológicos. Son determinados medios cuyas agendas editoriales y modelo comercial tienen el objetivo de polarizar identidades apelando a narrativas afectivas extremistas sobre temas que dividen y profundizan las divisiones como los derechos de inmigrantes, mujeres, minorías, comunidad LGBTQ y otras.

\section{Burbujas y polarización}

Considerando estas cuestiones se deben analizar los vínculos entre internet y polarización política. A simple vista, pareciera que la relación es indiscutible: el ascenso de internet coincide temporalmente con tendencias polarizantes en diversas democracias.

Quizás el argumento más difundido en esta línea sostiene que internet forma "burbujas de filtro" que mantienen a la ciudadanía en mundos relativamente cerrados ideológicamente, sin apertura a visiones diferentes. Las burbujas supuestamente operan como distribuidores de agrupamientos sociopolíticos; son separadoras de personas que refuerzan ideas negativas y hostiles frente a otros. Exacerban diferencias en tanto generan sentimientos fuertes de pertenencia a tribus determinadas que insisten en demarcar claras líneas divisorias entre grupos internos y externos.

Las burbujas son producto de dos procesos vinculados. Por una parte, la selección personal e intencional de rodearse de información que confirme creencias existentes y que aísle opiniones divergentes que contradigan o critiquen las propias convicciones. Por otra parte, los algoritmos de los medios sociales - las plataformas dominantes del tráfico digital— están diseñados para reforzar dietas de información a medida de los gustos y apetencias particulares. Con el objetivo de sostener el uso constante y generar experiencias placenteras en sus plataformas, los algoritmos no apuntan a mostrar ideas nuevas, desconocidas o ignoradas. Por el contrario, están diseñados para reforzar flujos de información que se ajustan a apetencias personales existentes según selecciones anteriores.

Esta combinación de procesos psicológicos de selección y confirmación de sesgos ideológicos personales y de la lógica corporativa destinada a maximizar tiempo de uso construye "cámaras de eco" que constantemente afirman creencias e ideologías personales más que exponer a los públicos a ideas desconocidas, revisar prejuicios o repensar sentimientos agresivos frente a otros.

Hoy en día, esta posición es de sentido común, mencionada frecuentemente por expertos y amateurs como el "gran culpable" de la polarización. 
De hecho, cuando fuera formulada originalmente por Eli Pariser (2011), fue una intuición más que un argumento basado en evidencia irrefutable que permitía sacar conclusiones categóricas. Era creíble porque intuitivamente tenía visos de realidad. Filtros y cámaras de eco son metáforas potentes, intrigantes y convincentes en sociedades con visibles y profundas diferencias sociales, mundos separados y vidas distantes unas de la otras. Cualquiera puede entender su presunta existencia y funcionamiento, sin necesidad de grandes teorías de la persuasión o evidencia masiva de efectos certeros.

En esta línea argumental se ubican declaraciones y trabajos posteriores. En su reciente libro, Cass Sunstein (2018 argumenta que, puesto que los medios sociales permiten crear menús comunicativos ajustados a características personales, causan serios problemas. Llevan al autoaislamiento y la personalización que son las fuentes de ideas falsas y promueven la polarización y la fragmentación. El problema es, en su opinión, que tales dinámicas disminuyen las posibilidades de encuentros no planeados, no anticipados con ideas diferentes, condición fundamental para la democracia, en tanto tiene el potencial de poder enfrentarnos con perspectivas no buscadas y diferentes a las nuestras que pueden modificar creencias y actitudes existentes.

En principio, esta posición suena convincente. Uno puede perfectamente imaginarse situaciones de opiniones diferentes, que viven en la comodidad de sus propias certezas, sin molestarse por saber si son reales, y que sostengan prejuicios funestos y fanáticos sobre sus presuntos y reales enemigos. Es factible que se conozca personalmente gente que encarna tal tipo usuario de internet (incluidos gente entrañable, familiar y amiga, o uno mismo) que se rodea de ideas y contenidos informativos concordantes y no se expone a opiniones y datos contrarios.

Esta especulación se asienta en argumentos de la psicología cognitiva sobre la selección de contenidos, el razonamiento motivado, y el sesgo de confirmación que tienen amplia circulación e influencia en círculos académicos y la intelligentsia. Pareciera que estamos destinados, predispuestos psicológicamente, sin diferencias sociales o culturales, a vivir en mundos informativos relativamente cerrados del resto. Estas tendencias enraizadas en (una interpretación de) la psicología humana adquiere enorme importancia en el mundo de la abundancia de información y entretenimiento, ya que proveen atajos para seleccionar rápidamente el enorme caudal existente. Se tiende a elegir información consistente con selecciones previas que permite no solamente obtener rédito social y placer personal, sino también ahorrar tiempo en la búsqueda constante de contenidos.

Sin embargo, el argumento que culpa a los medios digitales, especialmente a las plataformas sociales, y su tendencia a explotar determinados rasgos psicológicos polarizantes debe ser examinado con precaución, por más que 
parezca convincente. Es una nueva versión de argumentos intuitivos, apurados, equipados con evidencia mínima pero que son enormemente atractivos. Son una versión actualizada de la vieja línea analítica "mediacentrista" en estudios de comunicación sobre el "efecto poderoso de los medios" en la política, que apunta a encontrar responsables mediáticos de forma fácil y rápida sobre tendencias en la opinión pública y procesos políticos.

\section{Contraargumentos sobre la tesis de la burbuja}

¿Cuáles son las limitaciones del argumento sobre burbujas comunicacionales y polarización?

Estudios sobre la presunta polarización en medios digitales/sociales no encuentran resultados convincentes que demuestren tal hipótesis. De hecho, a mayor utilización de tales medios hay menor apoyo hacia ofertas políticas polarizantes. A la inversa, personas que discuten sobre política con gente de la misma raza, clase y grupo étnico en espacios no mediatizados son más proclives a apoyar causas polarizantes, especialmente ligadas a opciones de derecha (Boulianne et al, 2018).

Asimismo, la polarización afectiva — es decir, la intensificación de sentimientos más extremos hacia los propios y los "otros"-, no ocurre en todas las capas etarias de manera similar. Investigaciones en Estados Unidos muestran que la gente de mayor edad expresa una pronunciada intensificación ideológica a comparación de grupos jóvenes donde el proceso no tuvo la misma intensidad (Boxell et al, 2017). Esto es importante por varias razones: indica la necesidad de afinar el análisis en vez de hablar en sentido amplio sobre polarización de electorados sin tener en cuenta posibles diferencias sociales — edad, partido, género, etc.

Asimismo, esta conclusión es curiosa en tanto la población de mayor edad no es precisamente la que dedica mayor cantidad de tiempo al consumo de internet, lo cual podría sugerir una relación negativa entre internet y polarización - lo opuesto del presunto argumento de que la comunicación digital agudiza sentimientos extremistas. De hecho, estudios en varios países muestran que la televisión sigue siendo la principal fuente de información para ciudadanos de mayor edad.

La irónica vuelta de tuerca de este argumento es que las audiencias jóvenes que tienden a un mayor consumo de internet y noticias digitales están más expuestas accidentalmente a diferentes contenidos que sectores de más edad, que utilizan principalmente medios "tradicionales". Otro punto importante es que las poblaciones jóvenes están menos interesadas en política y son menos proclives a tener identidades partidarias o ideológicas fuer- 
tes y activas (Fletcher et al, 2020). Las poblaciones más polarizadas son quienes tienen identidades políticas más fuertes y consumen información con más frecuencia.

La polarización es más visible entre quienes expresan mayor interés por la política. No es un rasgo de la población en general. Los segmentos de la ciudadanía que participan en la política de diversas formas (votación, movilización pública, donaciones, trabajo voluntario en campañas electorales) son más proclives a tener opiniones más fuertes y extremas que la población en general.

Esta corriente se evidencia en plataformas como Twitter que concitan un público más politizado que la media poblacional, que sigue la política más de cerca y con mayor frecuencia, y que tiende a estar particularmente activo (Machado et al, 2018). Hay una "espiral de refuerzo" de actitudes y creencias dinamizada por el consumo de ciertos medios sociales, especialmente Twitter. Cuando se escucha a quienes piensan diferente es factible que haya un refuerzo de actitudes más que cambios de perspectivas o aumento de interés en entablar conversaciones o modificar las convicciones propias. Quienes se polarizan gracias a las plataformas digitales tienden a ser militantes y activistas. De ahí que tomar a Twitter como lugar esencial para sacar conclusiones sobre la polarización lleve a visiones parciales sobre la sociedad en general. Recordemos que Twitter como objeto de estudio está sobrerrepresentado en estudios sobre polarización digital por razones metodológicas en comparación, por ejemplo, a Facebook, WhatsApp y YouTube. Puesto que exhibe notorios sesgos demográficos (por educación, nivel socioeconómico, e interés en la política), es problemático sacar conclusiones generales sobre la polarización como si fuera un fenómeno uniforme a partir de tendencias en Twitter.

Que la digitalización de la comunicación pública lleva a la fragmentación de públicos según simpatías políticas es indudable. La fragmentación según contenidos de particular interés es tangible, como muestran numerosos estudios sobre el uso de información en medios sociales (especialmente Twitter), que grafican burbujas multicolores con limitadas conexiones vinculantes (ver Urman, 2019). Sin embargo, esto no implica que los públicos vivan en "cámaras de eco" perfectamente cerradas al resto. La fragmentación implica el afianzamiento de formas de intermediación comunicativa ancladas en lógicas partidarias, ideológicas y temáticas, pero no implica que los públicos estén encapsulados absolutamente.

De hecho, trabajos recientes (Bruns, 2019) cuestionan la visión de las burbujas mediáticas a la luz de evidencia que muestra escenarios de consumo/uso de contenidos y participación digital que no encajan en la caricatura de públicos secuestrados en cámaras de eco. Asimismo, hay estudios que 
sugieren que cuando públicos con fuertes sentimientos partidarios están expuestos a contenidos opuestos o diferentes de sus convicciones refuerzan actitudes negativas hacia otros (Bail et al, 2018). Es decir que la exposición a la diversidad opera como un bumerán que intensifica actitudes más que generar simpatía, entendimiento o interés por quienes están "del otro lado".

El problema es tomar estas tendencias, especialmente los presuntos efectos de Twitter, como barómetro de lo que ocurre en la población en general en cuestiones de polarización. Al facilitar formas de participación política, los medios digitales (en verdad, Twitter) fortalecen la polarización, no debido a presuntos fenómenos de cámaras de eco o burbujas informativas, sino porque intensifican sentimientos de identidad ideológica y partidaria (Dubois y Blank, 2018).

Aquí le cabe responsabilidad a la elite periodística, miembro natural y participe habitual de nichos hiper-politizados e ideologizados, de generar y perpetuar la percepción de polarización generalizada, recurriendo a estudios parciales que muestran evidencia. En realidad, es un fenómeno acotado, principalmente entre elites políticas y simpatizantes y activistas que no necesariamente son representativos de lo que ocurre en la opinión publica en general. Lo cual debería confirmarse con estudios longitudinales de opinión publica que consideren variables como el uso y frecuencia de medios. La convicción de vivir en sociedades absolutamente polarizadas refleja este sesgo profesional más que la sintonía con la ciudadanía en general, especialmente aquella desinteresada de la política, que presta atención esporádicamente a temas públicos, y que no es usuaria de Twitter.

Finalmente, otro punto confuso en el argumento sobre "burbujas informativas" es que la polarización no tiene similar grado en diferentes democracias (Boxell et al,2020). Hay variaciones de polarización afectiva. Esto es importante en tanto cuestiona la idea de que las "burbujas" y "cámaras de eco" tienen efectos similares, sin distinción de diferencias existentes —ya sean mediáticas, políticas, sociales. Es notable que la polarización más acentuada se observa en Estados Unidos- el país del fenómeno de los noticieros de cable afinadamente alienados con posturas ideológicas (especialmente el caso de Fox), intensas divisiones sociales y raciales, y cambios sustanciales en la composición racial y geográfica de los dos partidos mayoritarios. No pareciera que la polarización fuera producto única o principalmente de las características de internet o de los medios sociales. Por el contrario, hay una tamización y convergencia de influencias más que "efectos" poderosos de los medios sociales en polarizar al electorado. No hay efectos unidireccionales sino contextuales, filtrados por diferentes variables como características de identidades partidarias y ofertas y hábitos informativos.

En resumen, hay varios factores a considerar a la hora de determinar el impacto de las "burbujas": las diferencias demográficas importantes tanto 


\section{Silvio Waisbord}

en la polarización actitudinal como en el consumo de medios, el mayor consumo de plataformas digitales genera un grado más alto de exposición a contenidos diversos, y salir de la supuestas "burbujas" informativas no reduce sino que fortalece convicciones. La relación comunicación digital-sentimientos políticos es más compleja que lo sugerido por el conocido argumento sobre las burbujas (Bright et al,2020).

Frente al simplismo "burbujista", es preciso considerar las siguientes conclusiones que entienden la relación entre internet y polarización de forma más comprensiva y compleja.

Primero, la existencia de cámaras de eco no implica la ausencia de exposición a ideas diferentes, o que los públicos eviten completamente estar expuestos a ideas diferentes y contrarias a las propias. De hecho, en las supuestas cámaras de eco circulan ideas "del otro lado", si bien pueden estar filtradas por la cobertura del "lado propio".

Segundo, la exposición a ideas diferentes puede intensificar actitudes polarizantes, especialmente entre quienes ya tienen actitudes fuertes sobre ciertas ideologías y causas partidarias. La exposición a la diferencia, como concluyen diversos estudios en comunicación, no necesariamente genera mejores predisposiciones, tolerancia y apertura ideológica, sino que puede también reforzar actitudes negativas hacia otros. De hecho, los resultados son mixtos más que concluyentes.

Tercero, la polarización suele ser efecto de la exposición a medios que deliberadamente apuntan a ese objetivo. No es una cualidad de los medios tradicionales partidarios o digitales en su totalidad, sino de agentes mediáticos empecinados por razones empresariales en fomentar la exacerbación de identidades políticas combativas y polarizantes.

Cuarto, la polarización vehiculizada por "los medios" se refiere principalmente a determinadas capas poblacionales que tienen mayor interés por la política. Internet no solo agiganta las diferencias entre públicos "hiper informados/interesados" y "sub-informados/interesados" sino que facilita la polarización entre los primeros. Son estos quienes son más proclives a participar tanto de sitios políticamente homogéneos donde intercambian ideas con personas con convicciones afines y están expuestos deliberada o incidentalmente a ideas opuestas filtradas por redes sociales y medios ideológicamente afines. Los medios crean la impresión de que la sociedad está más polarizada de lo que realmente ocurre, y que todo tema es polarizado y estrictamente filtrado con miradas ideológicas y/o partidarias. En realidad, este es un fenómeno acotado a cierta parte de la ciudadanía.

Quinto, es erróneo generalizar sobre los "medios sociales' y sus supuestos efectos en la polarización. Twitter no es Facebook y Facebook no es YouTube. Mientras que Twitter facilita las dinámicas mencionadas anterior- 
mente, Facebook es más complejo por sus propias algoritmos y capacidades de la plataforma que permite diferentes tipos de interacciones y exposición a contenidos (además del perfil demográfico y político). Facebook es la rampa de entrada para un flujo enorme de públicos hacia los medios tradicionales como así también el sitio de formación de grupos cerrados de interés (incluidos partidarios). No hay lógica común en los medios sociales como se solía describir una lógica mediática y/o periodística única. De hecho, más allá que su objetivo sea sumar audiencias y maximizar tiempo en la plataforma, cada medio social tiene diferentes diseños de exposición a contenidos que van cambiando y ajustando según objetivos empresariales.

Sexto, la polarización necesita verse en un enfoque políticocomunicacional dentro del contexto histórico. El "burbujismo" peca a menudo de tener una visión de corto plazo y centrada en la tecnología, ignorando corrientes políticas que preceden a la revolución digital y que ahondan la polarización (especialmente entre segmentos específicos de la ciudadanía). En Estados Unidos, la polarización actual se remonta a un proceso visible desde hace medio siglo, tanto en las elites políticas como en ciertos segmentos del público, específicamente a partir de la reacción racista contra el movimiento de los derechos civiles y otros movimientos sociales que desafiaron la supremacía blanca y el patriarcado (Larkin y Lendler, 2019). En América Latina, se puede argumentar que la polarización en ciertos países no es radicalmente nueva, sino que es la continuación de clivajes políticos divisorios históricos entre derecha e izquierda, liberalismo y conservadurismo, y populismo y anti-populismo (Borda, 2018). Lo que en el pasado se combatía por periódicos y radio, hoy tiene a los medios tradicionales y digitales como escenarios centrales.

\section{Populismo, polarización y comunicación}

Sería limitado y equivocado pensar que la polarización política puede entenderse solamente analizando las estructuras y dinámicas de la comunicación pública digital. Esta es quizás la limitación más grave de argumentos puramente comunicacionales o que intentan explicar el fenómeno apoyándose únicamente en el análisis de los medios digitales. Así como el contexto mediático es importante para entender la polarización, es también necesario examinar variables políticas. Para decir lo obvio: el contexto político importa.

Aquí propongo discutir el significado del populismo en relación con la polarización en escenarios diversos tanto en sentido político como comunicacional. Es imposible entender la polarización contemporánea sin analizar el populismo. Por una parte, hay razones contextuales que requie- 


\section{Silvio Waisbord}

ren esta dimensión. El populismo ha sido una tendencia descollante en la política mundial en décadas recientes justamente cuando la polarización se volvió marca importante de la política. No hay región del mundo que haya sido inmune a la insurgencia populista. El populismo se convirtió en uno de los desafíos más claros para la democracia en tanto es un fenómeno político masivo, que alcanzo poder y notable influencia política en distintas regiones, cuyos principios están en conflicto y contradicción con la democracia liberal (Peruzzotti, 2017).

Como se sabe, populismo es una categoría ambigua y confusa — sujeto de infinitas discusiones y clarificaciones necesarias. Aquí no es mi intención revisar este extenso campo analítico y semántico plagado de confusión. Entiendo al populismo como un movimiento político al "borde del liberalismo" (Arditi, 2011) en tanto su visión de la política cuestiona principios esenciales de la democracia liberal — división de poderes, mecanismos de crítica, rendición de cuentas y transparencia, libertad de expresión y participación. Con esto no pretendo resolver discusiones interminables, sino ofrecer una definición operacional que sirva de guía analítica, especialmente considerando la variedad de populismos "suaves" e "intensos" (de la Torre, 2021).

Lo notable del populismo no es su vacío ideológico y capacidad de adoptar y adherirse a diferentes ideologías clásicas. El populismo se caracteriza por su escepticismo y oposición a los principios fundacionales del liberalismo que sustentan la democracia constitucional. Ofrece una visión rígidamente dualista de la política como eterno conflicto entre dos actores unificados (pueblo contra elites) y enemigos acérrimos. Moviliza resentimientos contra las elites definidas según cuestiones propias de cada experiencia histórica y nacional —oligarquía, imperialismo, expertos, medios de comunicación, intelectuales, empresas extranjeras. Se encarna en liderazgos carismáticos y demagógicos empecinados en debilitar cualquier forma de control que pueda poner cortapisas a la acción ejecutiva. Entiende al estado de forma caudillista donde el patronazgo y el nepotismo es común frente a los intereses del personal burocrático y técnico y la posición de los expertos.

Basado en estos principios y visión de la política, el populismo es proclive a la polarización (Handlin, 2018; McCoy et al,2018). Esto se debe no solamente a su continua visión del "otro" como enemigo, sino a entender la política en términos de campos estrictamente definidos, sin grises ni acuerdos posibles. Esto resulta en el contante fomento retórico de divisiones y en la defenestración de la oposición. La polarización quita incentivos para la negociación y el compromiso. Coloca al populismo donde solamente puede cumplir sus objetivos gozando de absoluto apoyo parlamentario o contraviniendo reglas establecidas y principios constitucionales. ¿Por qué negociar con quien se demoniza? Esta situación fácilmente se convierte en la ausen- 
cia de consenso, la parálisis política, la exacerbación de prejuicios y odios, y el fortalecimiento de actitudes extremas.

¿Cómo se mantiene comunicacionalmente tal visión populista? El populismo requiere dos elementos esenciales de la comunicación política: medios afines y leales, sumado a narrativas maniqueas (Waisbord, 2014).

El populismo contemporáneo emergió y se consolidó en la fragmentada ecología informativa de medios modernos y medios digitales. Por una parte, el populismo precisa un sistema de medios leal a su visión política, que incansablemente profundice divisiones, cante loas al talento infinito del Líder Adorado, y satanice al maléfico enemigo. Los medios ideológicamente afines son puramente instrumentales en tanto son entendidos como esenciales para apuntalar identidades afirmadas en torno a la polarización afectiva y la deslegitimación del Otro. Necesita colonizar tanto medios tradicionales como digitales. Precisa un collar de medios incondicionales, partidarios, ideológicos, sesgados abiertamente, que martillen los mismos mensajes sincronizados con las intenciones oficiales. No precisa la represión absoluta o la extinción de medios adversos, por más que en algunos casos, como en Europa del Este, Filipinas, y América Latina, el populismo en el gobierno haya tenido ese objetivo, una vez que fracasó su intento de conquistar a sus adversarios a través de recursos legales, la compra, y la presión. Se apoya también en dinámicas de medios sociales tanto para la difusión de mensajes oficialistas y personalistas (Amado y Waisbord, 2017) como para la agregación de simpatizantes en grupos abiertos o cerrados (Mazzoleni y Bracciale, 2018).

Experiencias populistas sugieren que la polarización es un proceso esencialmente "desde arriba" por parte de elites que aprovechan situaciones de crisis políticas, parálisis y descontento para identificar ejes diferenciables y ahondar divisiones. En este sentido, miembros de la elite política o políticos surgidos por fuera de la política utilizan hábilmente estructuras comunicacionales para su mensaje polarizante. Son quienes insisten con claves de divisiones mediante la retórica contra los grupos de poder, con el objetivo de sembrar y/o cosechar odios y descontento contra la política y sus instituciones (Tworzecki, 2019). Cuando las elites políticas están divididas en cuestiones fundamentales, hay posibilidades para que miembros o hábiles outsiders, con capital económico, político y/o mediático, activen la polarización. La polarización dentro de las elites causa la polarización pública, o en determinados segmentos a través de exposición mediática y discursos públicos (Druckman et al, 2013).

Las elites políticas, incluidos los candidatos insurgentes, son influencers claves que direccionan y traccionan la polarización en tanto gozan de amplia cobertura mediática o acceso directo (en medios sociales) a millones de 
seguidores. Son quienes hábilmente insertan temas divisorios que anclan identidades políticas. Estos temas varían principalmente según el populismo adquiera carácter de derecha o izquierda. Para la derecha contemporánea, los temas polarizantes son esenciales en la "guerra cultural" —identidad blanca, inmigración, minorías, nacionalismo, globalismo (Wojcieszak et al,2018). Para la izquierda, son las cuñas temáticas como oligarquía, poderes internacionales, neoliberalismo, nacionalismo. No son los medios por sí solos quienes "polarizan", sino las elites canalizadas por la cobertura mediática, ya sean medios afines ideológicamente o medios "masivos" que vehiculizan sus mensajes. Líderes políticos marcan temas y marcos interpretativos destinados a polarizar. Utilizan la fusión de medios analógicos y digitales para cultivar el culto de la personalidad (Govil y Baishya, 2018).

Asimismo, estudios recientes sugieren que la polarización populista vía medios se apoya fundamentalmente en medios tradicionales más que en medios digitales (con la excepción de Facebook). En el contexto europeo, la televisión comercial sumada a la lectura de los diarios sensacionalistas es habitual fuente de información entre votantes de populismos de derecha (Schulz, 2019).

La polarización populista funciona de acuerdo con la lógica amigo/enemigo que consiste en agitar la confrontación permanente con determinados actores sociales vistos como "el Otro a derrotar". Sobresalen en el imaginario populista contemporáneo la construcción de los medios, los organismos oficiales técnicos, los expertos, las universidades y la sociedad civil crítica, como el enemigo eterno, opuestos a la voluntad popular transmutada en el líder, el auténtico representante de los intereses nacionales.

Esto explica la obsesión populista con definir a determinados medios como enemigos - es central a la polarización como eje identitario. Aprovechan y realzan percepciones hostiles contra determinados medios en el electorado, medios que generalmente tienen posiciones críticas frente a sus candidaturas o gobiernos (Matthes et al,2019; Meeks, 2019; Waisbord, 2014). Lanzan acusaciones diversas frente a estos medios y utilizan etiquetas como la "prensa mentirosa" y la "prensa foránea" para descalificar su cobertura. En el caso del populismo de derecha, tal retórica se monta sobre convicciones preexistentes que desconfían, atacan y se burlan de los medios por su supuesto favoritismo por causas progresistas - actitudes que abarcan tanto a votantes conservadores como de extrema derecha (Fawzi, 2019; Figenschou e Ihlebæk, 2019). La baja confianza en los medios mainstream es un rasgo común en ciudadanos con simpatías de derecha tanto en Estados Unidos como en Europa.

Una lógica similar subyace a la oposición hacia estructuras de producción de conocimiento que difieren o cuestionan las verdades populistas de- 
clamadas por el líder, como indican las actuales presidencias de Trump, Orban, Bolsonaro, Modi, Ortega, y Maduro, entre otros. Aquí se señalan a instituciones despreciadas como enemigos. Incluye a organismos de gobierno (en principio independientes del ejecutivo) que producen conocimiento técnico como estadísticas e informes sobre una diversidad de temas - economía, empleo, pobreza, medio ambiente, salud, educación, derechos humanos, violencia, regulación de industrias. Asimismo, el populismo se opone por razones similares a organismos privados y sin fines de lucro como universidades y organizaciones de la sociedad civil que producen conocimiento que disputa narrativas oficiales.

La polarización apunta a crear y remarcar divisiones epistémicas ligadas a simpatías partidarias e ideológicas. Es desconocer y rechazar la posibilidad de conocimiento "autónomo" que no obedezca a cálculos estrictamente políticos. El conocimiento es movilizado como arma y herramienta de poder, que es imposible de comprender sin sus vínculos con la política. Y como la política se comprende como finamente dividida en dos campos, las instituciones están capturadas por estas dinámicas centrípetas. La polarización deliberada rechaza la visión del conocimiento como aproximación certera a la realidad y ofrece una visión dualista en cualquier ámbito de la sociedad. La polarización afectiva no tiene únicamente a los simpatizantes del "otro lado" en términos clásicamente políticos, sino también a sus supuestas usinas de información, datos y conocimiento (Ylä-Anttila, 2018).

Obviamente, las estrategias populistas como así también los obstáculos que enfrenta para la construcción de un régimen oficialista de información y conocimiento varían. En países donde el Estado ejerce un poder discrecional y una enorme influencia sobre la economía de los medios, las universidades, la sociedad civil y el ejecutivo, puede presionar o sujetar a los organismos de gobierno.. La polarización "desde abajo" puede ser facilitada por la presencia de influyentes medios afines, la desregulación de mercados de medios, el financiamiento de redes de conocimiento aliadas a insurgentes populistas. La polarización consolidada "desde arriba", después de que el populismo asume el poder, es más factible cuando existe una tradición de patronazgo, no hay contrafuerzas consolidadas y/o los mecanismos de control son débiles y fáciles de desarmar o cooptar.

Aquí es importante recordar que la desinformación es parte central de la estrategia polarizante del populismo. Obviamente, la desinformación y el post-factismo no son propiedades exclusivas del populismo, sino que son un fenómeno central y consuetudinario de la propaganda política. Lo notable del populismo es que la desinformación está engarzada con otros elementos mencionados - la constante profundización de divisiones, el rechazo retorico a cualquier tipo de negociación o compromiso, y el martilleo 
constante de teorías conspirativas. Hay una perspectiva instrumental de los medios ligada a la producción de verdades propias — sentidos que justifican creencias y por lo tanto rechazan cualquier versión alternativa. La obsesión por reforzar narrativas de legitimidad desecha datos inconvenientes y se basa en conocimientos y hechos a medida de los intereses oficiales y las convicciones existentes entre sus seguidores.

Seria equivocado omitir el hecho de que, así como el populismo polariza debido a su propia visión de la política, la oposición contra el populismo tiende a generar dinámicas similares en su frontal "resistencia". La concepción de la política como amigo/enemigo no es exclusiva del populismo, sino que es adoptada por sus adversarios que insisten con mantener un único eje divisorio político-mediático en su furibunda oposición y resistencia.

\section{Conclusión}

La polarización debe analizarse como resultado de la conjunción de dinámicas político-comunicacionales. El foco de análisis debe ser integrado y bifocal, que examine tanto tendencias en la comunicación pública como en la política.

Existen incentivos políticos y mediáticos que tienden a la polarización. Por una parte, la polarización mediática es redituable en tanto atrae audiencias politizadas y con fuertes identidades partidarias (Baldoni y Schuliaquer, 2020). Donde hay proximidad económica y estratégica entre medios y gobierno (y financiadores privados de la política) hay un interés común en un periodismo que constantemente remarque la oposición feroz hacia la fuerza política contraria. Medios polarizantes son atractivos para políticos interesados en ganar el favoritísimo de su base electoral y descollar sobre rivales dentro de la misma fuerza política. La polarización de los medios tradicionales es importante en tanto algunos son fuentes de información compartida y comentada en redes digitales. Han conseguido capitalizar sus ventajas comparativas en los mercados tradicionales para convertirse en sitios populares en el tráfico digital. A su vez, la debilidad o ausencia de mecanismos políticos y mediáticos que tiendan a la moderación contribuye a la polarización.

Aquí es importante no perder de vista que los medios no necesariamente contribuyen a la polarización de forma similar según sus posiciones editoriales. La evidencia de estudios en Estados Unidos y varios países europeos muestra que los medios conservadores ahondaron la polarización de la derecha pero que no existieron desarrollos similares al otro lado del espectro político. Es decir, la polarización hacia la derecha es atribuible, en parte a medios escritos, radio y televisión, pero este rasgo no es observado con la 
misma intensidad en el campo de la izquierda, liberal o progresista. Este hallazgo debiera ser cotejado en otras democracias, como en América Latina, para entender si hay procesos paralelos a ambos lados del espectro ideológico. Este punto se conecta con la cuestión de que la polarización no siempre ocurre de forma similar a izquierda y derecha.

La polarización es problemática por varias razones. En términos de estructuras de medios, tiene a dividir al periodismo tradicional en dos bandos bien marcados. La polarización desincentiva el tipo de periodismo equilibrado, amplio, comprehensivo, que cubra temas y ofrezca perspectivas por fuera de la férrea lógica bipartidaria o el maniqueísmo ideológico. La polarización promueve una diversidad limitada y debilita los espacios para la expresión de diferencias sociales y políticas que no entren en la lógica binaria. Esto refuerza la desinformación en tanto expone a los públicos a visiones filtradas por intereses estrechos.

Por esta razón, la polarización profundiza la crisis de la comunicación pública como espacio común de información y deliberación. Fortalece el clientelismo mediático y la manipulación partidaria de los medios de propiedad pública orientado según la lógica de la crítica constante del otro y la alabanza eterna de los propios. Prioriza identidades estrechamente partidarias o personalistas por sobre principios cívicos (Svolik, 2019). Así se profundiza la situación de verdades divididas - la posverdad como característica medular de la política polarizada donde la imposibilidad de acuerdos mínimos sobre modos de producción de conocimiento zanja el camino para la constante producción de verdades confeccionadas según la lógica política, personal y partidaria. La verdad no se entiende como acciones colectivas destinadas a cotejar diferencias y consensos en la vida pública, sino como la imposición de la voluntad política sobre un enemigo que necesita ser derrotado.

Una visión dialógica y pluralista de la comunicación pública que, entre otras virtudes, pueda amortiguar los embates de la polarización, enfrenta notables dificultades estructurales históricas y contemporáneas. Las razones son varias: la economía política de los medios, la debilidad inexorable del periodismo como gatekeeper común y dominante, la proliferación de opciones informativas, y la disrupción de la ecología mediática fraccionada en múltiples esferas digitales.

Desde una perspectiva que entiende la polarización mediáticacomunicacional como problemática para la democracia, en tanto socava las bases para la negociación y el reconocimiento de las múltiples diferencias de la vida pública, es importante analizar opciones y alternativas.

Quedan preguntas sin respuestas obvias para investigaciones futuras. ¿Qué responsabilidad le caben a los medios y plataformas digitales en 
“despolarizar”, asumiendo que esto sea deseable y posible? ¿Cómo entrever un sistema de medios más equilibrado, donde haya ofertas importantes y populares que no estén ligadas a la lógica de la polarización? ¿Pueden sobrevivir medios que intentan salir de esa lógica cuando los incentivos económicos y políticos consisten en alinearse con elites políticas y en la polarización afectiva de parte de la ciudadanía? ¿Qué ocurre cuando las elites políticas, o cierta parte, actúan de forma más "responsable" evitando apelar a temas (issues) polarizantes (Pérez Liñán, 2016)? Si las elites optaran por alternativas "moderadas" que evitaran profundizar identidades extremas, ¿cómo afectaría a los medios de información y al uso de medios sociales? ¿Hay un proceso de moderación ciudadana ligado al rol de las elites y su papel descollante en la generación y el foco diario de la información política?

Investigar estas preguntas puede ayudar a entender mejor no solamente las causas del entramado político-comunicacional que favorece la polarización, sino también alternativas para evitar sus peores consecuencias.

\section{Referencias}

Arditi, B. (2011) La política en los bordes del liberalismo. Diferencia, populismo, revolución, emancipación. Barcelona: Gedisa.

Bail, C. A., Argyle, L. P., Brown, T. W., Bumpus, J. P., Chen, H., Hunzaker, M. F., y Volfovsky, A. (2018). Exposure to opposing views on social media can increase political polarization. Proceedings of the National Academy of Sciences, 115(37), 92169221.

Baldoni, M., y Schuliaquer, I. (2020). Los periodistas estrella y la polarización política en la Argentina. Incertidumbre y virajes fallidos tras las elecciones presidenciales. Más poder local, (40), 14-16.

Bermeo, N. G. (2003). Ordinary people in extraordinary times: The citizenry and the breakdown of democracy. Princeton: Princeton University Press.

Birkinbine, B., Gómez, R., y Wasko, J. (Eds.). (2016). Global media giants. Londres: Routledge.

Borda, S. (2018). Presidenciales en Colombia: ¿polarización o deterioro de la conversación política? Nueva Sociedad, Mayo. Recuperado de https://goo. gl/a6vmNg.

Bornschier, S. (2019). Historical polarization and representation in South American party systems, 1900-1990. British Journal of Political Science, 49(1), 153-179.

Boulianne, S., Koc-Michalska, K.,y Bimber, B. Right-Wing Populism, Social Media and Echo Chambers in Western Democracies. En New Media E Society, 22(4).

Boxell, L., Gentzkow, M., y Shapiro, J. M. (2017). Is the internet causing political polarization? Evidence from demographics. Washington: National Bureau of Economic Research. 
Boxell, L., Gentzkow, M., \& Shapiro, J. M. (2020). Cross-Country Trends in Affective Polarization. Washington: National Bureau of Economic Research.

Bright, J., Marchal, N., Ganesh, B., y Rudinac, S. (2020). Echo Chambers Exist! (But They're Full of Opposing Views). Cornell University. Disponible en arXiv preprint arXiv:2001.11461. Recuperado de https://arxiv.org/abs/2001.11461.

Bruns, A. (2019). Are filter bubbles real? John Wiley \& Sons.

Dahlgren, P. M. (2019). Selective exposure to public service news over thirty years: The role of ideological leaning, party support, and political interest. The International Journal of Press/Politics, 24(3), 293-314.

Darr, J. P., Hitt, M. P., y Dunaway, J. L. (2018). Newspaper closures polarize voting behavior. Journal of Communication, 68(6), 1007-1028.

De la Torre, C. (2021) What do we mean by populism? En H. Tumber y S. Waisbord (Eds.), The Routledge Companion to Media, Dis/Misinformation and Populism. En prensa.

De la Torre, C. y E. Peruzzotti (Eds.) (2008). Populismo y nuevas democracias en América Latina. Quito: FLACSO.

Druckman, J. N., Peterson, E., y Slothuus, R. (2013). How elite partisan polarization affects public opinion formation. American Political Science Review, 107(1), 57-79.

Dubois, E., y Blank, G. (2018). The echo chamber is overstated: the moderating effect of political interest and diverse media. Information, Communication E Society, 21(5), 729-745.

Fawzi, N. (2019). Untrustworthy news and the media as "enemy of the people?" How a populist worldview shapes recipients' attitudes toward the media. The Intermational Journal of Press/Politics, 24(2), 146-164.

Figenschou, T. U., \& Ihlebæk, K. A. (2019). Challenging journalistic authority: Media criticism in far-right alternative media. Journalism Studies, 20(9), 12211237.

Fletcher, R., A. Cornia, y R. Kleis Nielsen (2020) How Polarized Are Online and Offline News Audiences? A Comparative Analysis of Twelve Countries Research Article. The International Journal of Press/Politics, 25(2), 169-195.

Garrett, R. K., Long, J. A., y Jeong, M. S. (2019). New Evidence on Group Polarization from Partisan Media to Misperception: Affective Polarization as Mediator.Journal of Communication, 69(5), 490-517.

Govil, N., y Baishya, A. K. (2018). The bully in the pulpit: Autocracy, digital social media, and right-wing populist technoculture. Communication Culture E Critique, 11(1), 67-84.

Guerrero, M., y Márquez-Ramírez, M. (Eds.) (2014). Media systems and communication policies in Latin America. Springer.

Handlin, S. (2018). The logic of polarizing populism: State crises and polarization in South America. American Behavioral Scientist, 62(1), 75-91. 


\section{Silvio Waisbord}

Iyengar, S., Sood, G., y Lelkes, Y. (2012). Affect, not ideology: A social identity perspective on polarization. Public opinion quarterly, 76(3), 405-431.

Laclau, E. (2005) La razón populista. Buenos Aires: FCE.

Larkin, P., y Lendler, M. (2019). United \& Divided: Distinctions in Polarization between Political Elites and the Public. Disponible en SSRN 3399568.

Levendusky, M. S. (2013). How Partisan Media Polarize America. Chicago: University of Chicago Press.

Machado, C., Kira, B., Hirsch, G., Marchal, N., Kollanyi, B., Howard, P. N., y Barash, V. (2018). News and political information consumption in Brazil: Mapping the first round of the 2018 Brazilian presidential election on Twitter. En Comprop Data Memo 2018, 4. Recuperado de https:/comprop.oii.ox.ac.uk/research/brazil2018/.

Matthes, J., Maurer, P., y Arendt, F. (2019). Consequences of Politicians' Perceptions of the News Media: A hostile media phenomenon approach.Journalism Studies, 20(3), 345-363.

Mazzoleni, G., y Bracciale, R. (2018). Socially mediated populism: the communicative strategies of political leaders on Facebook. Palgrave Communications, 4(1), 50.

McCoy, J., Rahman, T., y Somer, M. (2018). Polarization and the global crisis of democracy: Common patterns, dynamics, and pernicious consequences for democratic politics. En American Behavioral Scientist, 62(1), 16-42.

Meeks, L. (2019). Defining the Enemy: How Donald Trump Frames the News Media. En Journalism E' Mass Communication Quarterly, 1077699019857676.

Pariser, E. (2011). The filter bubble: How the new personalized web is changing what we read and how we think. Nueva York: Penguin.

Peck, R. (2019). Fox populism: Branding conservatism as working class. Cambridge: Cambridge University Press.

Pérez-Liñán, A. (2016). Democracia, Radicalización, y Agencia Política en América Latina. Revista Debates, 10(1), 11-30.

Peruzzotti, E. (2017). Populism as democratization's nemesis: The politics of regime hybridization. Chinese Political Science Review, 2(3), 314-327.

Prior, M. (2007). Post-broadcast democracy: How media choice increases inequality in political involvement and polarizes elections. Cambridge: Cambridge University Press.

Przeworski, A., y Sprague, J. (1986). Paper Stones: A History of Electoral Socialism. Chicago: University of Chicago Press.

Puche, J. S., Fernández, C. B., \& Virgili, J. R. (2018). Información política y exposición incidental en las redes sociales: Un análisis de Argentina, Chile, España y México. Doxa Comunicación: revista interdisciplinar de estudios de comunicación y ciencias sociales, (27), 19-42.

Sani, G., y Sartori, G. (1980). Polarización, fragmentación y competición en las democracias occidentales. En Revista de Derecho Político, (7).

Sartori, G. (1976). Parties and Party Systems: a framework for analysis. Cambridge: Cambridge University Press. 
Schulz, A. (2019). Where populist citizens get the news: An investigation of news audience polarization along populist attitudes in 11 countries. Communication Monographs, 86(1), 88-111.

Settle. Jamie E. (2018) Frenemies: How Social Media Polarizes America. Nueva York: Cambridge University Press.

Sunstein, C. R. (2018). \# Republic: Divided democracy in the age of social media. Princeton: Princeton University Press.

Svolik, M. W. (2019). Polarization versus democracy. Journal of Democracy, 30(3), 2032.

Szabó, G., Norocel, O. C., y Bene, M. (2019). Media Visibility and Inclusion of Radical Right Populism in Hungary and Romania: A Discursive Opportunity Approach. Problems of post-communism, 66(1), 33-46.

Tucker, J. A., Guess, A., Barberá, P., Vaccari, C., Siegel, A., Sanovich, S., Stukal, D. y Nyhan, B. (2018). Social media, political polarization, and political disinformation: A review of the scientific literature.. Recuperado de https:// papers.ssrn.com/sol3/papers.cfm?abstract_id=3144139.

Turow, J. (1997). Breaking up America: Advertisers and the new media world. University of Chicago Press.

Tworzecki, H. (2019). Poland: A Case of Top-Down Polarization. En The ANNALS of the American Academy of Political and Social Science, 681(1), 97-119.

Urman, A. (2019). Context matters: political polarization on Twitter from a comparative perspective. Media, culture Ev society, 42(6). Recuperado de https:// journals.sagepub.com/doi/10.1177/0163443719876541.

Waisbord, S. (2000a). Media in South America: Between the rock of the state and the hard place of the market. En J. Curran y S. Park (Eds.), De-Westernizing media studies, 50-62. Londres: Routledge.

Waisbord, S. (2000b). Repensar la prensa en las democracias latinoamericanas. Sala de Prensa 2 (22).

Waisbord, S. (2014). Vox populista: Medios, periodismo, democracia. Barcelona: Gedisa.

Wojcieszak, M., Azrout, R., y De Vreese, C. (2018). Waving the red cloth: Media coverage of a contentious issue triggers polarization. Public Opinion Quarterly, 82(1), 87-109.

Ylä-Anttila, T. (2018). Populist knowledge: 'Post-truth' repertoires of contesting epistemic authorities. European Journal of Cultural and Political Sociology, 5(4), 356-388. 


\title{
Palabras clave
}

Polarización — medios digitales — comunicación pública — populismo desinformación

\section{Key words}

Polarization — digital media - public communication — populism disinformation

\begin{abstract}
The purpose of this paper is to examine the relationship between public communication and contemporary political polarization. From a review of recent global literature, it is proposed that polarization is the product of the combination of political and communication phenomena. It is wrong to understand polarization as a product solely associated with trends in digital communication. It is necessary to recognize the move towards more extreme positions of populisms and the loss and fragmentation of moderate positions (left or right) as well as the role of «traditional» media in fostering affective polarization. The overrepresentation of strong political feelings coupled with the mobilizing power of social and cultural cleavages deepens binary oppositions. Polarization as a political and media strategy pays off. In today's mediated communication, appealing to polarizing discourse pays off either in terms of audience and publicity as well as symbolic compensation on digital platforms - followers, popularity, relevance. Likewise, inequality in political participation, inclined in favor of people with strong partisan and ideological feelings, and the popularity of information media that aim to feed and stir up such feelings also underpin polarization.
\end{abstract}

